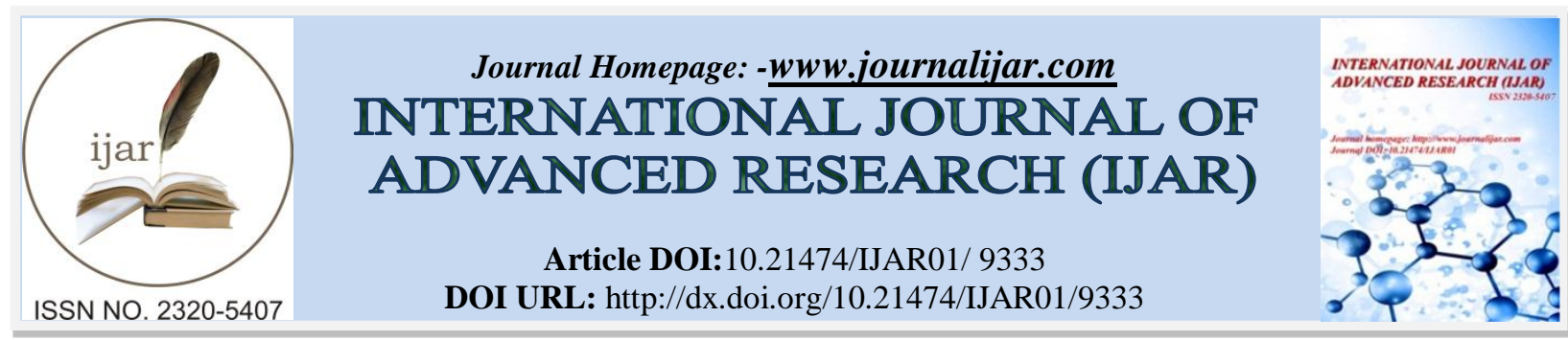

RESEARCH ARTICLE

\title{
MOBILIZING A MOBILE SURGICAL TEAM AT THE DISTRICT LEVEL, A COST EFFECTIVE STRATEGY FOR CATARACT SURGERY IN MALISOCIAL REHABILITATION, VISUAL FUNCTIONNING AND QUALITY OF LIFE OUTCOMES.
}

\author{
Seydou Bakayoko ${ }^{1}$,Moro Sidibé ${ }^{1}$, Nouhoum Guirou ${ }^{1}$, Rodrigue R.ELIEN.G.Y ${ }^{1}$, Amassagou Dougnon ${ }^{1}$, \\ Mamadou Togo ${ }^{1}$, Abdoulaye N.Coulibaly ${ }^{1}$, Ali Konikpo ${ }^{1}$, Nouhoum Touré ${ }^{1}$, Mahamat A.Dicko ${ }^{1}, J^{2}$ ean \\ François Schémann ${ }^{2}$. \\ 1. Institute of African Tropical Ophthalmology, BP 248, Bamako, Mali. \\ 2. Université Bordeaux 2 (EA 3677 et Centre René Labusquière) Bordeaux, France.
}

\section{Manuscript Info}

Manuscript History

Received: 03 May 2019

Final Accepted: 05 June 2019

Published: July 2019

Key words:-

Cataract surgery, Africa, strategy, Quality of life, outcome.

\section{Abstract}

Objectives:-To compare, in the region of Mopti region (Mali), the impact of a cataract surgery practised in a regional hospital (strategy 1 or fixed strategy) with a surgery close to the patients at the district level (strategy 2 or advanced strategy) on patient reported quality of life and visual functioning as well as on social rehabilitation.

Methods:-Two samples of 100 and 199 people operated on for cataract in the fixed and advanced strategies respectively, were included in this study and were submitted at questioned on perceived vision and quality of life (IOTAQOL).

Results:-Social conditions improved dramatically in both strategies, Most of men were able again to sustain their families $(86,0 \%$ and $93,9 \%$ in strategies 1 and 2 respectively) and women to participate in housekeeping (87,8\% and $88,2 \%$ respectively). The gains in QOL scores were high and equivalent in both strategies. These scores were strongly linked with the presence of an intraocular lens, with the ability to work and to fulfil his/her family duty. The gains in Perceived vision scores were equals in both strategies and strongly linked with postoperative visual acuity and with the presence of an intraocular lens. Conclusion:-Cataract surgery allows a dramatic socioeconomic reinsertion and a quality of life improvement whatever the strategy adopted.

Copy Right, IJAR, 2019,. All rights reserved.

\section{Introduction:-}

Cataract is the main cause of blindness worldwide accounting for more than $50 \%$ of this blindness (1). In West African countries such as Mali the number of persons operated on cataract is quite small despite the presence of ophthalmic surgical facilities in most of the regional hospitals. We hypothesised that one of the barrier was the distance to travel for reaching the regional hospital and that moving a surgical team from the regional hospital toward the district medical centres by diminishing the distance and the cost for the patients could significantly increase the demand. 
In the previous paper we have presented the visual outcomes and the costs for both strategies. Functional results were excellent and equivalent as $92.5 \%$ of patients operated on in the district centres by the mobile team (strategy called "advanced strategy") had a best corrected vision higher or equal to $6 / 19 \mathrm{vs} 98 \%$ among patients operated on at the regional centre (strategy called "fixed strategy").

We wanted also collect information on the impact of these two strategies on patient reported quality of life and visual functioning as well as on social rehabilitation.

\section{Methods:-}

\section{Methods and study design have already been presented.}

The study was a non randomized trial of patients recruited at the Mopti ophthalmic centre compared with patients operated on by the same team moving to seven different district general hospitals. It addressed both clinical, non clinical (visual function, QOL, satisfaction and social rehabilitation), and economical outcomes. Patients over 40 years of age with operable cataract and best corrected visual acuity worse than 0.1 in both eyes were enrolled. Patients were recruited from the Mopti hospital for the fixed strategy and from the district campaigns conducted by the regional ophthalmic team. Patients were followed up to 3 months after surgery. Pseudophakic patients did not received distance vision correction and aphakic patients received +10 diopter glasses after delivery.

Preoperatively after clinical examination, information on the study and informed consent signature, patients were administered the quality of life and visual functioning questionnaires. At the three month visit they were interviewed using the same questionnaires. Other questions were then asked on satisfaction with surgery and whether they would accept surgery on the second eye. Social and economic insertion of patients into their communities was also appreciated by direct questions concerning work ability. For men a question was asked on their ability to buy ingredients, which means he has the monetary resources for buying all ingredients necessary to add to the basic cereal (meat, fish, vegetables and spices for sauce). To fulfil this duty is of great importance in Malian society. To women a question was asked on their ability to participate to the housekeeping tasks.

The development methodology and the psychometric properties of the IOTA QOL have been presented elsewhere (2). Briefly, we developed at IOTA a quality of life questionnaire from the African patients' perspective. In particular, we started from the expressions used by the patients themselves in their own language, the Bambara, so as to develop a more valid and well adapted to the ethno-linguistic context of the sahelian populations. IOTAQOL questionnaire is categorised along four dimensions: mobility, socio-economic impact, social well being, and finally skill; it includes 26 questions. The additional six questions subscale concerning women exclusively are designed to address specific women concerns in the African context, such a being able to contribute to household chores, cooking foods, etc. Secondly this questionnaire was translated in Fulabe language from the Bambara and back translated into Bambara by an independent translator. IOTAQOL was administered to the patients before surgery and three months after in Bambara or Fulabe depending on the mother language of patients. For some patients belonging to the Dogon ethnic group and not undersanding Fulabe or Bambara languages, a translation was verbally done in the field by an dogon interpreter understanding Fulabe or Bambara.

Testing visual acuity is necessary for assessing visual function of individuals, for assessing the quality of interventions. However it is not sufficient, and does not make it possible to know what people with a visual deficiency feel nor to assess the perceived improvement after cataract surgery. It is possible to assess visual functioning by administering a questionnaire querying everyday visual problems as perceived by the patients themselves. Validated questionnaires that attempt to quantify "perceived vision" have been developed for developed countries $(\mathbf{3}, \mathbf{4})$ However, the several instruments that have been developed and validated in Europe and in the USA may not be appropriate for use in Africa. Therefore we used a questionnaire developed in India by Ellwein et al. (5) and already adapted for sub-Saharan Africa (6). The 13 questions aimed at reflecting the different theoretical dimensions of vision: general by a question assessing overall visual function, visual perception, visual field, adaptation to light or to darkness, visual search, discrimination of colours, depth perception and finally dazzling. The sum of the scores of each sub-scale provided a "visual functioning" score ranging theoretically from 14 for the more severe cases to a maximum of 43 for the bests. The French version of this questionnaire was translated into Bambara and into Fulabe language by professional recognised translators. These translations were then back translated into French by other independent translators. The questionnaires were administered in Bambara or in Fulabe depending on the patient native language. 
The same translating procedure was used for the other independent questions on satisfaction or ability to work, etc. Interviewers were trained at IOTA before the start of the study over a one week period.

\section{Data management and analysis}

For each strategy mean subscale and global scores are presented with their standard deviation. A within treatment effect size was computed for each strategy. Effect size is computed by dividing the mean scores increase after surgery by the standard deviation of mean score before intervention.

Between strategy groups comparisons of QOL and visual functioning scores at three months were tested by analysis of variance. An analysis of variance was used to examine the association between questionnaire scores, visual acuity and other determinants such as gender, age, work ability, other pathologic conditions and marital status. Independent associations between questionnaire scores and these determinants were also examined by multiple regression analysis adjusted for age and gender.

\section{Results:- \\ Population}

Between September 2014 and June 2014, 210 persons were included in the study and operated on cataract in the district hospitals by the mobile team; 199 were examined at the third month control. During the same period, 104 patients were included and operated on, 100 being examined at three months. No patients refused to be interviewed either at baseline or at follow up three month visit.

The average age was similar in the two strategies, 66 years for the advanced one and 64.8 years for the fixed one. Males were more numerous than female, 53\% in the fixed strategy and $56.8 \%$ in the advanced one; In both strategies most of patients were no more working (respectively $91 \%$ and $82 \%$ for fixed and advanced strategy). Most of men were not in position to buy the ingredients for feeding their family (only $35.8 \%$ were still able to fulfil this duty in fixed strategy and $36.6 \%$ in advanced strategy). For women only $2.1 \%$ in fixed strategy and $17.0 \%$ in advanced strategy were able to participate in housekeeping.

\section{Social outcomes}

Three months after surgery a dramatic change was evidenced in the social condition of most operated persons. In the fixed strategy $90.0 \%$ were able to work and 92.5 in the advanced strategy. Most of men were able to buy the ingredients $(86.0 \%$ and $93.9 \%$ in the fixed and advanced strategy respectively). We could observe the same figures for women since $87.8 \%$ were able to participate in housekeeping in the fixed strategy and $88.2 \%$ in the advanced. Most of operated persons were very satisfied or satisfied (89\% and $96 \%$ in strategy I and II respectively) and wanted to be operated on their second eye (99\% and $96.5 \%$ respectively).

\section{QOL outcomes}

Baseline Quality of life scores were not significantly different between the two groups (50.54 in fixed strategy versus 52.16 in advanced strategy, $\mathrm{p}=0.10)$.

All subscale scores increased (Table 2) considerably three months after surgery and the total scores reached 72.21 and 73.79 in fixed and advanced strategy respectively). The total score for the advanced strategy was significantly higher than in the fixed strategy $1(\mathrm{P}<0.0001)$. Nevertheless, the gains from cataract surgery three months after surgery were not significantly different between both strategies (Table 3 ).

Analysing the association of QOL scores at D90 with other determinants or outcome indicators. We found a positive link with visual acuity and with the presence of an IOL. QOL final scoring was strongly associated with the ability of working and of buying ingredients for men or housekeeping for women (Table 4). This QOL score was also positively linked with advanced strategy $(\mathrm{P}<0,001)$, with the male gender and with a married status.

The multiple regression model explaining QOL outcomes demonstrated the positive effect of the presence of an IOL, of the advanced strategy and of working ability.

\section{Visual function outcomes}

Total visual functioning score was slightly higher at baseline in advanced strategy (18.86) than in fixed strategy (16.62) $\mathrm{P}=0.0006$. All subscale scores increased (table 2) considerably three months after surgery and the total 
scores reached 36.65 and 37.41 in fixed and advanced strategies respectively). The total score for the advanced strategy was significantly higher than in fixed strategy $(\mathrm{P}=0.004)$.

Nevertheless, the gains from cataract surgery three months after surgery were not significantly different between both strategies (Table 3).

Analysing the association of visual functioning scores at D90 with other determinants or outcome indicators (Table 4). We found a positive link with visual acuity $(\mathrm{P}=0.003)$ and with the presence of an IOL $(0.0009)$. Visual functioning final scoring was strongly associated with the ability of buying ingredients for men $(\mathrm{P}<0.0001)$, but not with the ability of working nor of housekeeping for women $(\mathrm{P}=0.12)$. This score was also positively linked with advanced strategy $(\mathrm{P}=0.004)$ but not with the gender or with the marital status.

The multiple regression model explaining visual functioning outcomes demonstrates the positive effect of a visual acuity superior or equal to 0.3 , of the presence of an IOL and of working ability.

The mean gain by three months after surgery were not different either for QOL or for visual functioning. (Table 3) The within treatment effect size were very large in both strategies, between 2.8 and 10.1 for visual functioning scores and between 0.8 and 3.67 for QOL scores. Effect size of 0.3 or less are considered small, those around 0.5 as moderate and those above 0.8 are large.

\section{Discussion:-}

Satisfaction of patients after surgery was very high, reaching or superior to $90 \%$. Nevertheless the rate of satisfaction was significantly superior in the advanced strategy. Whatever the strategy, most of the operated persons would agree to be operated on the second eye.

Those figures are then very different from the observation of Singh et al. (7) in India who found that only half of the patients operated during eye camps were satisfied compared with $80 \%$ of satisfied patients if operated in a regional hospital.

The most important finding of our study was to evidence that cataract surgery allows a dramatic socioeconomic reinsertion only three months after surgery. More than 9 patients on 10 were able to work after surgery compared to 1 or 2 on 10 before. This astonishing high coming back in the productive sector explains the increase in revenue among operated persons. It explain that most of men became able to buy the ingredients and therefore to accomplish their familial duty and to recover their social dignity.

The increase appeared to be most important in advanced strategy (93.9\%) compared to fixed strategy (86.0\%), but it not reached the level of signification $(\mathrm{P}=0.09)$.

Concerning women, in the context of traditional African societies, to be able to participate to the household tasks could be a good indicator or rehabilitation and of social reinsertion. Thus cataract surgery allowed to 9 women on 10 to accomplish their household tasks and to participate again to familial activities.

Visual functioning scores before surgery appears very close of those of the study carried out in Mopti in 2000 (6) among visually impaired persons. .After surgery, scores of all studied dimensions had doubled whatever the strategy.

The global score was significantly more important in case of success (defined as visual acuity superior or equal to 0.3 with the best correction) $(\mathrm{P}=0.003)$ and in case of implantation. It also increases with the level of satisfaction.

Measuring quality of life in traditional African context imply using a culturally adapted instrument. We used the IOTAQOL questionnaire that had been elaborated from interview of visually impaired persons This questionnaire aims at exploring different aspects of daily life, mobility, skills, well being or social adaptation. For all dimensions we could observe a significant amelioration only three months after surgery, whatever the strategy. The total final score was significantly higher in the advanced strategy as well as the social and the well-being scores.

. Not surprisingly the QOL score was positively linked with the visual outcome and with the presence of an IOL. 
It was also significantly associated with working ability and for men with the ability to buy the ingredients. The comparison of the mean scores of "perceived vision" at D 90 according to gender does not show a significant difference between men and women. However, the mean scores for "quality of life" are significantly higher for men. This could reflect the observation that old women often lived alone and were either single or widowed whereas men are usually married and had some type of social support $(\mathbf{8 , 9})$. Indeed in our sample, $52 \%$ of women are unmarried and only $9 \%$ of men. The IOTA QOL questionnaire was specifically adapted to the people of rural regions of Sahelian Africa and correspond to their cultural environment. This instrument has proved to discriminate between groups of patients of different categories of visual impairment (2) and it proves in this survey to be sensitive to clinical changes after cataract surgery.

\section{Conclusion:-}

Cataract, the first cause of curable cecitis, is the source of bad quality of life and difficulties of social integration. These troubles can be resolved by surgery.

Table 1:-Variance analysis of outcomes by strategy

\begin{tabular}{|c|c|c|c|c|}
\hline & & Strategy I & Strategy II & $\mathrm{P}$ value \\
\hline \multirow[t]{2}{*}{ Visual acuity } & Preoperative $>$ LP & 14.00 & 13.00 & 0.8 \\
\hline & Postoperative $\geq 6 / 19$ & 98.50 & 92.50 & 0.052 \\
\hline \multirow[t]{2}{*}{ Working } & Before surgery & $9.0 \%$ & $18.0 \%$ & \\
\hline & After surgery & 90.0 & 92.5 & 0.46 \\
\hline \multirow[t]{2}{*}{ Buy ingredients } & Before surgery & $35.8 \%$ & $36.6 \%$ & 0.92 \\
\hline & After surgery & $86.0 \%$ & $93.9 \%$ & 0.09 \\
\hline \multirow[t]{2}{*}{ Housekeeping } & Before surgery & 2.1 & 17.0 & 0.01 \\
\hline & After surgery & 87.8 & 88.2 & 0.93 \\
\hline \multirow[t]{2}{*}{ QOL } & Before surgery & 50.54 & 52.16 & 0.10 \\
\hline & After surgery & 72.71 & 73.79 & 0.0000 \\
\hline \multirow[t]{2}{*}{ Women QOL } & Before surgery & 6.77 & 7.17 & 0.25 \\
\hline & After surgery & 13.65 & 15.03 & 0.009 \\
\hline \multirow[t]{2}{*}{ Perceived vision } & Before surgery & 16.62 & 18.86 & 0.0006 \\
\hline & After surgery & 36.65 & 37.41 & 0.004 \\
\hline Satisfaction & & $89 \%$ & $96 \%$ & \\
\hline Second eye & & $99 \%$ & 96.5 & \\
\hline
\end{tabular}

Table 2:-Scores (SD) of QOL and Perceived visoin by strategy

\begin{tabular}{|l|r|r|r|r|r|r|l|}
\hline \multicolumn{1}{|c|}{ Scores QDV D 0 } & Strategy I & \multicolumn{1}{c|}{ SD } & & Strategy II & \multicolumn{1}{l|}{ SD } & & P value \\
\hline Mobility & 12,57 & 3,41 & & 13,48 & 3,38 & & 0.03 \\
\hline Well being & 15,56 & 0,98 & & 15,35 & 0,85 & & 0.06 \\
\hline Social & 10,95 & 2,48 & & 11,18 & 2,36 & & 0.42 \\
\hline Skills & 11,46 & 2,47 & & 12,04 & 2,65 & & 0.03 \\
\hline QOL global & 50,54 & 8 & & 52,16 & 8,01 & & 0.10 \\
\hline Women scores & 6,77 & 1,84 & & 7,17 & 2,11 & & 0.27 \\
\hline & & & & & & & \\
\hline \multicolumn{1}{|c|}{ Scores QDV D 90 } & Strategy I & \multicolumn{1}{c|}{ SD } & effect size & Strategy II & SD & effect size & \multicolumn{1}{c|}{ P value } \\
\hline Mobility & 19,32 & 1 & 2,0 & 19,51 & 0,84 & 1,8 & 0.07 \\
\hline Well being & 17,27 & 0,79 & 1,7 & 17,51 & 0,78 & 2,5 & 0.01 \\
\hline Social & 17,55 & 1,96 & 2,7 & 18,45 & 1,86 & 3,1 & 0.000 \\
\hline Skills & 18,07 & 0,9 & 2,7 & 18,31 & 1,3 & 2,4 & 0.047 \\
\hline QOL global & 72,21 & 3,29 & 2,7 & 73,79 & 3,2 & 2,7 & 0.0000 \\
\hline Women scores & 13,65 & 2,69 & 3,7 & 15,03 & 3,67 & 3,7 & 0.009 \\
\hline & & & & & & & \\
\hline \multicolumn{1}{|c|}{ Scores PV* D 0 } & Strategy I & SD & & Strategy II & SD & & P value \\
\hline GS* & 1,04 & 0,2 & & 1,09 & 0,29 & & 0.09 \\
\hline VP* & 5,11 & 1,55 & & 6,01 & 1,92 & & 0.000 \\
\hline VF* & 1,27 & 0,45 & & 1,45 & 0,51 & & 0.002 \\
\hline
\end{tabular}




\begin{tabular}{|l|r|r|r|r|r|r|l|}
\hline DP* & 1,27 & 0,45 & & 1,49 & 0,53 & & 0.000 \\
\hline SA* & 7,93 & 2,36 & & 8,81 & 2,8 & & 0.007 \\
\hline Total & 16,62 & 4,5 & & 18,86 & 5,67 & & 0.0006 \\
\hline & & & & & & & \\
\hline Scores PV D 90 & Strategy I & \multicolumn{1}{|c|}{ SD } & effect size & Strategy II & SD & effect size & \multicolumn{1}{c|}{ P value } \\
\hline GS & 3,05 & 0,33 & 10,1 & 3,04 & 0,26 & 6,7 & 0.77 \\
\hline VP & 10,99 & 0,83 & 3,8 & 11,44 & 0,81 & 2,8 & 0.0000 \\
\hline VF & 2,9 & 0,3 & 3,6 & 2,86 & 0,34 & 2,8 & 0.39 \\
\hline DP & 2,93 & 0,26 & 3,7 & 2,95 & 0,24 & 2,8 & 0.51 \\
\hline SA & 16,75 & 1,09 & 3,7 & 17,11 & 1,14 & 3,0 & 0.016 \\
\hline Total & 36,65 & 2,23 & 4,5 & 37,41 & 2,14 & 3,3 & 0.004 \\
\hline
\end{tabular}

* $\mathrm{PV}=$ Perceived vision, $\mathrm{GS}=\mathrm{Global}$ score, $\mathrm{VP}=$ Visual perception, $\mathrm{VF}=\mathrm{Visual}$ field, $\mathrm{DP}=\mathrm{Depth}$ perception, $\mathrm{SA}=$ sensory adaptation

Table 3:-Gains from cataract surgery by strategy Mean gain 3 months after surgey (SD)

\begin{tabular}{|l|r|r|}
\hline \multirow{2}{*}{ Strategy } & Mean gain by 3 months after surgery (SD)* & \\
\cline { 2 - 3 } & QOL (IOTAQOL) & Visual function \\
\hline All & $21.64(7.65)$ & $19.04(5.58)$ \\
\hline Strategy I & $21.67(7.21)$ & $20.03(4.68)$ \\
\hline Strategy II & $21.63(7.88)$ & $18.55(5.9)$ \\
\hline Difference & 0.05 & 1.48 \\
\hline P value & 0.90 & 0.14 \\
\hline
\end{tabular}

* All were significant gains compared with baseline values: $\mathrm{p}$ value $<0.001$

Table 4:-QOL and Perceived vision at D90, by determinants

\begin{tabular}{|c|c|c|c|c|c|}
\hline & & QOL & & PV & \\
\hline Determinant & Type & Score & $\mathrm{P}$ value & Score & $\mathrm{P}$ value \\
\hline \multirow[t]{2}{*}{ Gender } & Male & 73.77 & 0.01 & 37.35 & 0.053 \\
\hline & Female & 72.64 & & 36.92 & \\
\hline \multirow[t]{2}{*}{ Age } & $<66$ & 73.53 & 0.16 & 37.28 & \\
\hline & $>65$ & 72.99 & & 37.04 & 0.35 \\
\hline \multirow[t]{2}{*}{ Marital status } & Married & 73.55 & 0.009 & 37.23 & 0.12 \\
\hline & Unmarried & 72.54 & & 36.97 & \\
\hline \multirow[t]{2}{*}{ Visual outcome } & $\mathrm{VA}>0.2$ & 73.36 & 0.024 & 37.26 & 0.003 \\
\hline & $\mathrm{VA}<0.3$ & 71.65 & & 35.47 & \\
\hline \multirow[t]{2}{*}{ IOL } & Yes & 73.58 & $<0.0001$ & 37.33 & 0.0009 \\
\hline & No & 71.43 & & 36.14 & \\
\hline \multirow[t]{2}{*}{ Strategy } & I & 72.21 & 0.00007 & 36.65 & 0.004 \\
\hline & II & 73.79 & & 37.41 & \\
\hline \multirow[t]{3}{*}{ Satisfaction } & 1 & 73.75 & 0.07 & 38.02 & 0.00002 \\
\hline & 2 & 73.26 & & 37.07 & \\
\hline & 3 & 71.72 & & 35.5 & \\
\hline \multirow[t]{2}{*}{ Working } & Yes & 73.53 & 0.00001 & 37.27 & 0.12 \\
\hline & No & 70.40 & & 35.92 & \\
\hline \multirow[t]{2}{*}{ Buy ingredients (men) } & Yes & 74.09 & $<0.0001$ & 37.57 & 0.00007 \\
\hline & No & 70.71 & & 35.07 & \\
\hline \multirow[t]{2}{*}{ Housekeping (women) } & Yes & 72.86 & 0.02 & 37.19 & 0.12 \\
\hline & No & 70.68 & & 34.87 & \\
\hline
\end{tabular}

Table 5:-Logistic regression of QOL three months after surgery

\begin{tabular}{|l|l|l|l|l|}
\hline & QOL at D 90 & & PV at D 90 & \\
\hline VA $\geq 0.3$ & 1.21 & 0.12 & 1.52 & 0.006 \\
\hline Gender & 1.36 & 0.000 & 0.54 & 0.03 \\
\hline
\end{tabular}




\begin{tabular}{|l|l|l|l|l|}
\hline Age & -0.91 & 0.01 & -0.35 & 0.16 \\
\hline Strategy II/I & 1.38 & 0.000 & 0.70 & 0.008 \\
\hline Working & 2.73 & 0000 & 1.05 & 0.016 \\
\hline $\begin{array}{l}\text { Peroperative } \\
\text { incident }\end{array}$ & -1.50 & 0.002 & -0.96 & 0.004 \\
\hline
\end{tabular}

\section{References:-}

1. Wang W, Yan W, Müller A, He M. A Global View on Output and Outcomes of Cataract Surgery With National Indices of Socioeconomic Development.Invest Ophthalmol Vis Sci. 2017,1;58(9):3669-3676

2. Leplege A, Schémann JF, Diakité B, Touré O, Ecosse E, Jaffré Y. A new condition specific quality of life measure for the blind and the partially sighted in sub-Saharan Africa, the IOTAQOL: methodological aspects of the development procedure. Quality of Life Research. 2007,15, 1373-1382

3. Steinberg EP, Tielsh JM, Schein OD, et al. The VF-14. An index of functional impairment in patients with cataract. Arch Ophthalmol. 1994,112, 630-8.

4. Prager T, Chuang A, Slater C, Glasser J, Ruiz R and The Cataract Outcome Study Group. The Houston Vision Assessment Test (HVAT): Reliability and validity. Ophthalmic Epidemiology .2000,7, 87-102..

5. Ellwein LB, Fletcher A, Negrel AD \& Thulasiraj RD.Quality of life assessment in blindness interventions. International Ophthalmology, 1995,18, 263-268

6. Schémann JF, Leplege A, Keita T, Resnikoff S.From visual function deficiency to handicap: measuring visual handicap in Mali. Ophthalmic Epidemiol.2002, 9, 133-48.

7. Singh A, Garner P, Floyd K.Cost-effectiveness of public-funded options for cataract surgery Mysore, India. The Lancet.2000, 355: 180-4.

8. Fassin D.Handicaps physiques, pratiques économiques et stratégies matrimoniales au Sénégal. Social Science and Medicine, 1991,33, 267-272.

9. Jaffré Y \& Moumouni A."Etre aveugle " La Cécité, entre une définition épidémiologique et sociale.Bull Soc Path Ex .1993,86:295-299. 